American Journal of Applied Sciences 5 (1): 22-28, 2008

ISSN 1546-9239

(C) 2008 Science Publications

\title{
Prediction of Permanent Deformation of Pavement's Unbounded Layers Based on Cyclic Triaxial Tests
}

\author{
B. Žlender \\ University of Maribor, Faculty of Civil Engineering, \\ Smetanova 17, 2000 Maribor, SI Slovenia
}

\begin{abstract}
This research presents an analytical model for determining permanent deformation of pavement's sub-grade and unbound granular base and sub-base material due to cyclic traffic loading. The model is given for interpreting results of repeated load triaxial tests. It considers long term elastoplastic behavior and resilient behavior of sub-grade and unbound granular material. Permanent deformations are expressed as a function of the number of loading cycles and the spherical component and the deviatoric component of the repeated loading. The permanent axial deformation is given as a function of the resilient modulus and the secant modulus for different states of spherical and distortional stresses, and number of loading cycles. By analytical derivation it is presented that the normalized permanent axial strain can be expressed with the modulus values and the parameter $D$. The moduli are expressed as the functions of the spherical stress component and the distortional stress component. The magnitude of normalized permanent axial strain depends on the limit value of the resilient modulus and ratios between resilient and secant modulus. The parameter $D$ gives the shape of the change of the normalized permanent axial strain with the number of cycles, and is a function of the change of modules with the number of cycles. The applicability of the presented model is demonstrated on the practical example of a repeated load triaxial test of sub-base granular material.
\end{abstract}

Keywords: pavement, sub-grade, unbound base/sub-base granular material, repeated load triaxial test, resilient modulus, secant modulus, permanent axial strain

\section{INTRODUCTION}

Pavements are layered structures which are characteristically exposed to low permanent stresses due to self weight and relatively high repeating local loads due to traffic. Traffic influences are demonstrated as dynamic loading at each passage of the repeating load due to a high number of vehicle passages. As a result of each individual dynamical loading compressive and extensional deformation of road layers appear. These deformations are partly elastic and partly inelastic. Inelastic deformations of the individual layers of structures gradually increase due to repeating loading. Through time this is indicated as settlements and unevenness of surface course layer of the pavement. A triaxial apparatus was proved to be appropriate for the determination of elastic and inelastic deformations due to traffic loading.

Analytical models were developed for the description of plastic deformation of unbound granular material. Barksdale ${ }^{[1]}$ found that the permanent axial strain deformation was proportional to the number of load cycles at different stress states. After 1972 different authors proposed models for describing the development of permanent axial deformations at different stress states and proportionally with the number of loading cycles $N$. However, most models were not used in practical calculations in analyses and design of road structures. The weakness of such models is their inapplicability in calculations using FEM. Hornych model ${ }^{[2]}$ was proved to be applicable and it was used as a comparative one in our research.

In the Laboratory of Soil Mechanics and Foundation Engineering (LMT) the research was performed ${ }^{[3]}$ to investigate the behavior of the unbound granular material under repeating traffic loading and to determine factors which influence its deformability.

The paper presents an analytical model which interprets permanent deformations considering long term elastoplastic behavior and resilient behavior of unbound granular material. The model describes permanent deformation as a function of resilient modulus and secant modulus. The model is prepared for the interpretation of repeated load triaxial tests results

Corresponding Author: $\quad$ Bojan Zlender, University of Maribor, Faculty of Civil Engineering, Smetanova 17, Postal Code: SI-2000, Maribor, Slovenia, Tel: + 38622294 300, Fax: + 38622524179 
of sub-grade and unbound granular base and sub-base material.

\section{MATERIALS AND METHODS}

Repeated load triaxial test: The paper considers repeated load triaxial tests of unbound mixtures performed according to variation cell pressure method and to constant cell pressure method. Some of the results obtained in the laboratories of the company ZAG Ljubljana $^{[4]}$ and $\mathrm{LMT}^{[5]}$ were analyzed.

To execute repeated load triaxial tests the proper test equipment is required that comprises: a triaxial cell, a press with appurtenant equipment, measurement equipment, a control system and a data storage system, and computer hardware and software.

The calculation of strength characteristics regarding measured deformation and stress parameters is performed after each individual investigation phase. Measured are the following quantities: cell pressure $\sigma_{3}$, vertical stress $\sigma_{l}$, vertical strain $\varepsilon_{l}$ and radial strain $\varepsilon_{3}$.

\section{RESULTS AND DISCUSSION}

The vertical settlement of pavement is being treated as a consequence of pavement materials and sub-grade materials deformations. The resilient strains $\varepsilon^{r}$ and the permanent strains $\varepsilon^{p}$ are determined for pavement layers and sub-grade material at different stress conditions.

Resilient modulus: The resilient strain $\varepsilon^{r}$ is taken as the unloading strain from the maximum dynamic stress down to the static contact stress.

The $k-\theta$ model $^{[6]}$ could be used to describe the resilient behavior of unbound granular material in repeated load triaxial tests. In this model, the Poisson's ratio $v$ is constant. With the $k-\theta$ model and a given stress path, we are able to solve the elastic problem. The inelastic problem is solved using a constant Poisson ratio $v$ and the Young's modulus E. The expression of volume strains $\varepsilon_{v}{ }^{r}$ and shear strains $\varepsilon_{q}^{r}$ and modulus $E, K, G$ is done using Boyce ${ }^{[7]}$.

The resilient modulus depends on mean and deviatoric stress. Considering both, Uzan et al. ${ }^{[8]}$ expressed a new model. The modified AASHTO equation has been included for modeling this behavior.

$$
M_{r}=K_{1} \cdot \sigma_{a} \cdot\left(\frac{\sigma_{1}+2 \cdot \sigma_{3}}{\sigma_{a}}\right)^{K_{2}} \cdot\left(\frac{\tau_{o c t}}{\sigma_{a}}+1\right)^{K_{3}}
$$

where $\sigma_{a}$ is reference stress $(101 \mathrm{kPa}), \sigma_{l}, \sigma_{3}$, are principal stresses, $\tau_{o c t}$ is octahedral shear stress and $K_{l}$, $K_{2}, K_{3}$ are model parameters.

Permanent deformation: The determination of permanent deformations of unbound granular material is based on repeated load triaxial tests from standards ${ }^{[9-}$ ${ }^{10]}$ that differ in some details.

The magnitude and development of permanent deformations depend on static stress state of the material, magnitude of cyclic load, magnitude of spherical and deviatoric cyclic load component and the relationship between them, the number of loading cycles, and physical properties of material (density, water content).

The limit state plastic strains are calculated in agreement with the Hornych model ${ }^{[2]}$. The normalized axial permanent strain is described with:

$\varepsilon_{1}^{p^{*}}=A \cdot F(N)=A \cdot\left[1-\left(\frac{N}{100}\right)^{-B}\right]$

where the parameters $A$ and $B$ define deformation growth with number of loading cycles $N$. The parameter $A$ denotes the limit of the function of permanent axial deformations, the parameter $B$ denotes its deflection.

Suggested model for determining permanent deformation: It is derived from measurements of repeated load triaxial test. The material responds to the repeating traffic load with the axial vertical strain $\varepsilon_{l}$ and the radial strain $\varepsilon_{2}$. The stress in material during individual loading varies between the chosen maximum value $q_{\max }$ and the chosen minimum value $q_{\min }$. The strain at each individual loading reaches the certain maximum value in compression $\varepsilon_{l}^{\text {com }}$ and the certain minimum value at unloading $\varepsilon_{l}^{\text {ext }}$. The difference between them is the resilient strain $\varepsilon_{l}^{r}$.

The reproduction of cyclic loading increases the strains $\varepsilon_{I}{ }^{c o m}(N)$ and $\varepsilon_{l}^{\text {ext }}(N)$, while the difference between them $\varepsilon_{l}^{r}(N)$ decreases, when material hardens, and increases, when material softens.

Figure 1 shows the relationship between the distortional stress component $q$ and the axial vertical strain $\mathcal{E}_{l}$. The relationship between the reloading stress

$\Delta q$ and the strain $\varepsilon_{l}^{s}(N)=\Delta \varepsilon_{l}^{c o m}(N)$ is described with the secant modulus $E^{s}$, while the relationship between the unloading stress $\Delta q$ and the unloading resilient strain $\varepsilon_{l}^{r}(N)=\Delta \varepsilon_{l}^{e x t}(N)$ is described with the resilient modulus $E^{r}$. 


$$
\begin{aligned}
& E^{s}(N)=\frac{\Delta q}{\varepsilon_{1}^{c}(N)} \\
& E^{r}(N)=\frac{\Delta q}{\varepsilon_{1}^{r}(N)}
\end{aligned}
$$

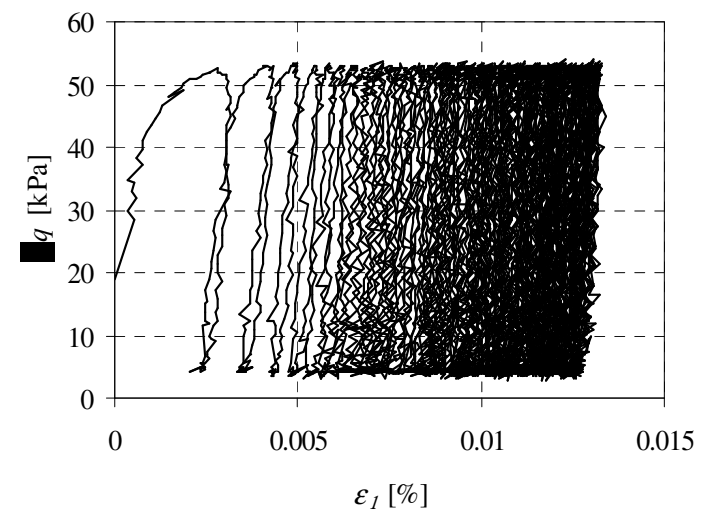

Fig 1: Deviatoric stress $\Delta q$ vs. vertical axial strain $\varepsilon_{l}$

The change of plastic strain between cycles is:

$$
\begin{aligned}
& \frac{d \varepsilon_{1}^{p}(N)}{d N}=\varepsilon_{1}^{c}(N)-\varepsilon_{1}^{r}(N) \\
& =\frac{\Delta q}{E_{\lim }^{r}\left(N_{\lim }\right)} \cdot\left(\frac{E_{\lim }^{r}}{E^{s}(N)}-\frac{E_{\lim }^{r}}{E^{r}(N)}\right)
\end{aligned}
$$

The value of the modulus $E^{s}$ and $E^{r}$ increases with the number of cycles and reaches or approaches the maximum value of the resilient modulus at a sufficiently high number of cycles:

$$
E_{\lim }^{r} \geq E^{r}\left(N_{\lim }\right) \quad E_{\lim }^{r} \geq E^{s}\left(N_{\lim }\right)
$$

The change of the modulus $E^{s}$ and $E^{r}$ and the plastic strain $\varepsilon_{l}^{r}(N)$ with cycles can be described in the form of functions. The change of plastic strains for $N>100$ are $\varepsilon_{l}^{r^{*}}(N)$. The functions can have the following form:

$$
\begin{aligned}
& \frac{E_{\lim }^{r}}{E^{s}(N)}=C_{1} \cdot\left(\frac{N}{100}\right)^{-D_{1}}+1 \\
& \frac{E_{\lim }^{r}}{E^{r}(N)}=C_{2} \cdot\left(\frac{N}{100}\right)^{-D_{2}}+1 \\
& \text { and }
\end{aligned}
$$

$$
\left.\frac{d \varepsilon_{1}^{p^{*}}(N)}{d N}=\frac{\Delta q}{E_{\lim }^{r}} \cdot C \cdot\left(\frac{N}{100}\right)^{-D}\right)
$$

For $N=100$

$$
E_{100}^{r}=E^{r}(N=100) \quad E_{100}^{s}=E^{s}(N=100)
$$

$C_{1}=\frac{E_{\lim }^{r}}{E_{100}^{s}}-1 \quad C_{2}=\frac{E_{\text {lim }}^{r}}{E_{100}^{r}}-1$

and

$$
C=C_{1}-C_{2}=\frac{E_{\mathrm{lim}}^{r}}{E_{100}^{s}}-\frac{E_{\mathrm{lim}}^{r}}{E_{100}^{r}}
$$

The solution of Eq. 5 only has the meaning if

$$
E_{\lim }^{r} \geq E^{r}(N) \geq E^{s}(N) \quad C_{1} \geq C_{2}
$$

in case

$$
E^{s}(N)=E^{r}(N) \quad C_{1}=C_{2}
$$

the strain is only elastic.

The parameters $D_{1}$ and $D_{2}$ can be determined using the method of least square deviation. Differentiating Eq. 5 leads to:

$$
\begin{aligned}
& -\frac{\Delta q}{E_{\lim }^{r}} \cdot C \cdot D \cdot\left(\frac{N}{100}\right)^{-D-1}= \\
& =\frac{\Delta q}{E_{\lim }^{r}} \cdot\left(-C_{1} \cdot D_{1} \cdot\left(\frac{N}{100}\right)^{-D_{1}-1}+C_{2} \cdot D_{2} \cdot\left(\frac{N}{100}\right)^{-D_{2}-1}\right)
\end{aligned}
$$

Hence parameter $D$ follows, which is:

$D=\frac{C_{1} \cdot D_{1}-C_{2} \cdot D_{2}}{C_{1}-C_{2}}$

For constant resilient modulus $E^{r}$ parameter $C_{2}=0$ and $D=D_{l}$.

The progress of the permanent axial strain $\varepsilon_{l}^{p^{*}}(N)$ is obtained integrating Eq. 5:

$d \varepsilon_{1}^{p^{*}}(N)=\frac{\Delta q}{E_{\lim }^{r}} \cdot \int_{100}^{n} C \cdot\left(\frac{N}{100}\right)^{-D} \cdot d N$

After derivation follows:

$$
\begin{aligned}
& d \varepsilon_{1}^{p^{*}}(N)=\frac{\Delta q}{E_{\lim }^{r}} \cdot \frac{100 \cdot C}{(D-1)}\left[1-\left(\frac{N}{100}\right)^{-(D-1)}\right] \\
& =\varepsilon_{1}^{r} \cdot \frac{100 \cdot C}{(D-1)}\left[1-\left(\frac{N}{100}\right)^{-(D-1)}\right]
\end{aligned}
$$

The permanent axial strain $\varepsilon_{l}^{p^{*}}(N)$ can be thus expressed with the modulus $E^{s}$ and $E^{r}$ and the parameter $D$. 
Am. J. Applied Sci., 5 (1): 22-28, 2008

Table 1: Physical properties of stone materials

\begin{tabular}{ccccc}
\hline $\begin{array}{c}\text { Type of stone } \\
\text { material }\end{array}$ & $\begin{array}{c}\text { Coefficient } \\
\text { of uniformity } C_{u}[- \\
]\end{array}$ & $\begin{array}{c}\text { Coefficient of } \\
\text { curvature } C_{c}[-]\end{array}$ & $\begin{array}{c}\text { Density } \\
\rho_{d}\left[\mathrm{~g} / \mathrm{cm}^{3}\right]\end{array}$ & $\begin{array}{c}\text { Optimal } \\
\text { water content } \\
w_{\text {opt }}[\%]\end{array}$ \\
\hline Uncrushed mixture & 43 & 3.5 & 2.20 & 5.1
\end{tabular}

The progress of the permanent axial strain for an arbitrary state of distortional and spherical stress component, can be given, if values of the modulus $E^{s}(p, q)$ and $E^{r}(p, q)$ and the parameter $D(p, q)$ are expressed as the functions of $p$ and $q$. The stated parameters are expressed using Eq. 1, in such a manner that we get the set of equations from the set of tests, and the values of model parameters $K_{l}, K_{2}, K_{3}$ are expressed using the method of least square deviation.

The strain $\varepsilon_{l}^{p^{*}}(N)$ can be expressed regarding spherical and distortional stress components $p, q$ :

$$
\begin{aligned}
& \mathcal{E}_{1}^{p^{*}}(N, p, q)=\varepsilon_{1}^{p^{*}}\left(N, p_{0}, q_{0}\right) \cdot f(p) \cdot f(q) \\
& =\varepsilon_{0} \cdot f(p) \cdot f(q)
\end{aligned}
$$

where the characteristic value of the permanent axial strain $\varepsilon_{0}(N)$ is given at chosen values of the spherical stress component $p_{0}$ and the distortional stress component $q_{0}$. For a chosen value of the permanent axial strain $\mathcal{E}_{I}^{p^{*}}(N)$, the values of $p$ and $q$ can be expressed from Eq. 19 and the so called deformation lines at a certain number of loading cycles $N$ are obtained. The limit values that lead to failure give the so called failure line of the material.

Example: The applicability of the presented model was verified on the practical example of repeated load triaxial test of sub-grade and base course granular material. The Drava river sub-grade sand and gravel was investigated using repeated load triaxial tests ${ }^{[3,11]}$. The results showed the influence of preloading, compaction grade of the material and its moisture content to the deformability. The analysis of development of permanent axial deformations of gravel in the Mura region due to repeated loading was performed $^{[4,12]}$. Types of stone material were determined with regard to the quantity of crushed grains in gravel and to water content. The electro-filter granular material was also investigated ${ }^{[5]}$. Samples with and without reinforcements were tested.

Drava river gravel: The investigation of natural gravel quality from the existent deposits in the Drava river region was done in laboratories and in field. Repeated load triaxial tests were performed. Samples of stone material were tested in cycles at different water content. The set of tests on samples with the water content $w=$ $w_{\text {opt }} \pm 0.5 \%$ re considered. Physical properties of the analyzed type of stone material are given in Table 1.

The determination resilient modulus $E_{100}^{r}$ and the secant modulus $E_{100}^{s}$ can be obtained from the series of tests Table 4 with a small number of cycles $(N=100)$. However, parameters $E_{l i m}^{r}$ and $D$ are unknown.

Parameters $E_{\text {lim }}^{r}$ and $D$ can be obtained only from the tests with higher number of cycles. Table 3 presents input data and the modulus $E_{100}^{r}, E_{100,}^{c} E_{\text {lim }}^{r}$ for tests with the number of cycles $N>20000$.

From the measurements modules $E_{100}^{r}$ and $E_{l i m}^{r}$, the secant modulus $E_{100}^{s}$ and the parameter $D$ are given. From the results of parameters for a set of tests, modules $E_{100}^{r}(p, q), \quad E_{100}^{s}(p, q), \quad E_{l i m}^{r}(p, q)$ and the parameter $D(p, q)$ are determined using Eq. 1 and the method of least square deviation. Table 2 presents values of the model parameters $K_{1}, K_{2}, K_{3}$.

Table 2: The calculated model parameters $K_{1}, K_{2}, K_{3}$

\begin{tabular}{cccc}
\hline & $K 1$ & $K 2$ & $K 3$ \\
\hline$E_{\text {lim }}^{r}$ & 757 & 0,632 & $-0,012$ \\
$E^{r}{ }_{100}$ & 599 & 0,754 & $-0,010$ \\
$E^{s}{ }_{100}$ & 590 & 0,710 & $-0,010$ \\
\hline
\end{tabular}

For each test the value of normalized permanent axial strain $\varepsilon_{l}^{p^{*}}(N)$ is calculated, and the comparison is given with a measured value Fig. 2.

Table 3 presents measured and calculated parameters for tests with the number of cycles $\mathrm{N}>$ 20000. Table 4 presents calculated parameters and the

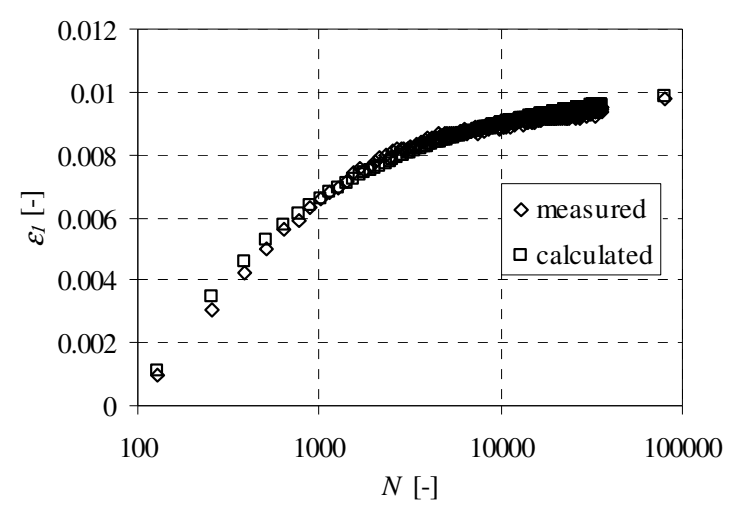

Fig. 2: Measured and calculated normalized permanent axial deformation $\varepsilon_{l}^{p^{*}}$ vs. the number of loading cycles $N$ 
Am. J. Applied Sci., 5 (1): 22-28, 2008

Table 3: Parameters for a set of tests with $N>20000$

\begin{tabular}{ccccccccc}
\hline $\begin{array}{c}\text { Spherical } \\
\text { stress } \\
p(\mathrm{kPa})\end{array}$ & $\begin{array}{c}\text { Deviatoric } \\
\text { stress } \\
q(\mathrm{kPa})\end{array}$ & $\begin{array}{c}\text { Stress } \\
\text { ratio } \\
q / p(-)\end{array}$ & $\begin{array}{c}\text { Secant } \\
\text { modulus } \\
E_{100}^{s}(\mathrm{kPa})\end{array}$ & $\begin{array}{c}\text { Resilient } \\
\text { modulus } \\
E^{r}{ }_{100}(\mathrm{kPa})\end{array}$ & $\begin{array}{c}\text { Resilient } \\
\text { modulus } \\
E_{\text {lim }}^{r}(\mathrm{kPa})\end{array}$ & $\begin{array}{c}\text { Parameter } \\
C\left(10^{-5}\right)\end{array}$ & $\begin{array}{c}\text { Parameter } \\
D(-)\end{array}$ & $\begin{array}{c}\text { Value } \\
C /(D-1) \\
\left(10^{-6}\right)\end{array}$ \\
\hline 77 & 50 & 0,7 & 81 & 83 & 125 & 1,5 & 1,77 & 20 \\
96 & 100 & 1,0 & 143 & 145 & 149 & 1,0 & 1,34 & 29 \\
167 & 200 & 1,2 & 161 & 167 & 204 & 4,0 & 1,68 & 59 \\
83 & 100 & 1,2 & 109 & 111 & 143 & 1,6 & 1,82 & 20 \\
83 & 100 & 1,2 & 137 & 139 & 139 & 1,1 & 1,41 & 25 \\
37 & 50 & 1,4 & 53 & 54 & 79 & 1,5 & 1,22 & 67 \\
35 & 50 & 1,4 & 68 & 71 & 91 & 3,0 & 1,40 & 75 \\
35 & 50 & 1,4 & 60 & 63 & 83 & 4,0 & 1,55 & 73 \\
127 & 200 & 1,6 & 145 & 154 & 179 & 8,0 & 1,79 & 101 \\
117 & 200 & 1,7 & 149 & 154 & 167 & 4,5 & 1,43 & 104 \\
48 & 100 & 2,1 & 72 & 77 & 91 & 8,0 & 1,30 & 267 \\
33 & 70 & 2,1 & 56 & 58 & 64 & 5,0 & 1,39 & 128
\end{tabular}

Table 4: Calculated parameters for a set of tests with $N=100$

\begin{tabular}{ccccccccc}
\hline $\begin{array}{c}\text { Spherical } \\
\text { stress } \\
p(\mathrm{kPa})\end{array}$ & $\begin{array}{c}\text { Deviatoric } \\
\text { stress } \\
q(\mathrm{kPa})\end{array}$ & $\begin{array}{c}\text { Stress } \\
\text { ratio } \\
q / p(-)\end{array}$ & $\begin{array}{c}\text { Secant } \\
\text { modulus } \\
E_{l 00}^{s}(\mathrm{kPa})\end{array}$ & $\begin{array}{c}\text { Resilient } \\
\text { modulus } \\
E_{l 00}^{r}(\mathrm{kPa})\end{array}$ & $\begin{array}{c}\text { Resilient } \\
\text { modulus } \\
E_{\text {lim }}^{r}(\mathrm{kPa})\end{array}$ & $\begin{array}{c}\text { Parameter } \\
C\left(10^{-5}\right)\end{array}$ & $\begin{array}{c}\text { Parameter } \\
D(-)\end{array}$ & $\begin{array}{c}\text { Norm. axial } \\
\text { perm. strain } \\
\mathcal{E}_{l}^{p^{*}}(\%)\end{array}$ \\
\hline 50 & 50 & 1 & 77 & 80 & 98 & 2,1 & 1,60 & 0,35 \\
70 & 70 & 1 & 97 & 102 & 121 & 3,4 & 1,60 & 0,56 \\
90 & 90 & 1 & 116 & 123 & 142 & 4,5 & 1,60 & 0,74 \\
110 & 110 & 1 & 132 & 142 & 161 & 5,4 & 1,60 & 0,91 \\
130 & 130 & 1 & 148 & 160 & 179 & 6,4 & 1,60 & 1,06 \\
33 & 50 & 1,5 & 58 & 59 & 76 & 1,3 & 1,49 & 0,26 \\
47 & 70 & 1,5 & 73 & 75 & 94 & 2,8 & 1,49 & 0,57 \\
60 & 90 & 1,5 & 87 & 90 & 110 & 4,2 & 1,49 & 0,85 \\
73 & 110 & 1,5 & 99 & 104 & 125 & 5,4 & 1,49 & 1,09 \\
87 & 130 & 1,5 & 111 & 118 & 138 & 6,5 & 1,49 & 1,32 \\
25 & 50 & 2 & 47 & 47 & 63 & 0,2 & 1,39 & 0,06 \\
35 & 70 & 2 & 59 & 61 & 78 & 2,0 & 1,39 & 0,51 \\
45 & 90 & 2 & 71 & 73 & 92 & 3,6 & 1,39 & 0,91 \\
55 & 110 & 2 & 81 & 84 & 104 & 5,0 & 1,39 & 1,27 \\
65 & 130 & 2 & 91 & 95 & 115 & 6,3 & 1,39 & 1,60 \\
30 & 90 & 3 & 53 & 54 & 71 & 1,8 & 1,17 & 0,87 \\
37 & 110 & 3 & 61 & 62 & 80 & 3,5 & 1,17 & 1,72 \\
43 & 130 & 3 & 68 & 70 & 89 & 5,0 & 1,17 & 2,51
\end{tabular}

normalized axial permanent strain $\varepsilon_{l}^{p^{*}}$ for a set of tests with the number of cycles $N=100$.

A course of the normalized axial permanent deformation $\varepsilon_{l}^{p^{*}}$ could be expressed as a function of the deviatoric stress $q$ and the spherical stress $p$ for each number of cycles, see Fig. 3. The relation between the normalized axial permanent deformation $\varepsilon_{l}^{p^{*}}$ and the deviatoric stress $q$ for the constant spherical stress $p$ (viewed in individual planes in the $\varepsilon_{l}^{p^{*}}-p-q$ space) is obtained.

The relation between the spherical stress component $p$ and the deviatoric stress component $q$ at a certain value of the normalized axial permanent strain $\varepsilon_{l}^{p^{*}}$, gives the so called deformation envelopes. Deformational envelopes decrease with the number of cycles $N$ Fig. 4. 


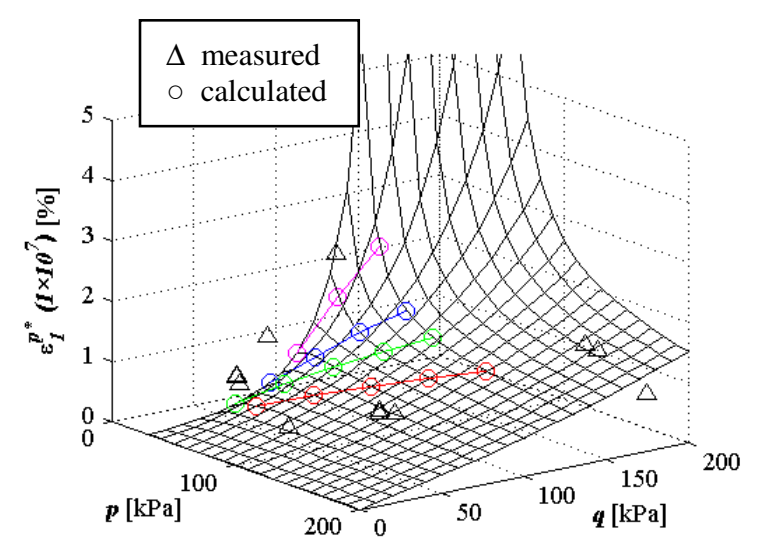

Fig. 3: Normalized axial permanent deformation $\mathcal{E}_{l}^{p^{*}}(N)$ vs. spherical stress $p$ and deviatoric stress $q$

Deformational envelopes increase with the increase of axial permanent strain and approach the failure envelope, which represents a limit state of the relation $q / p$, see Fig. 5.

\section{CONCLUSION}

The analytical model for determining permanent deformation of sub-grade and unbound granular material due to cyclic repeating traffic loading is given. material due to cyclic repeating traffic loading is given. The model is given for the interpretation of triaxial repeated load test results and for considering long term elastoplastic behavior and resilient behavior of subgrade and unbound granular material.

Permanent deformations are expressed as a function of the number of loading cycles $N$ and the

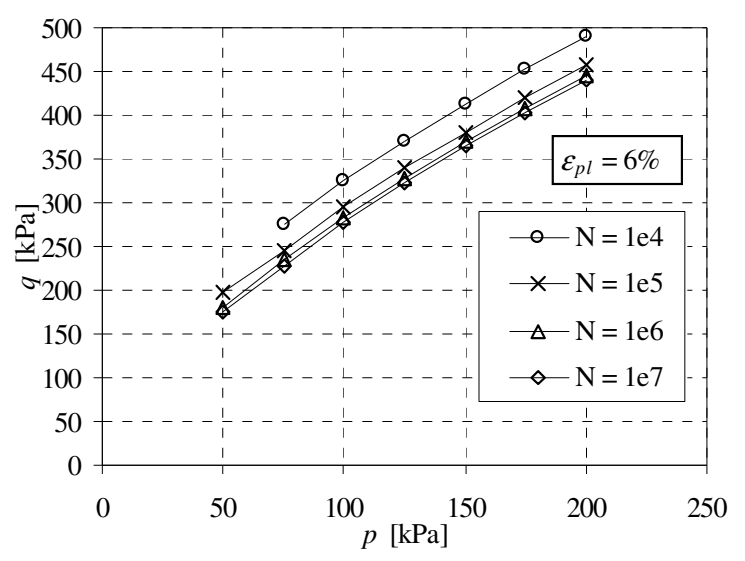

Fig. 4: Deformation envelopes for different number of cycles $N$ spherical component of the cyclic loading $p$ and the deviatoric component of the cyclic loading $q$.

The permanent axial deformation of material is given as function of the resilient modulus and the constrained modulus for different states of spherical and distortional stresses and number of loading cycles.

The analytical derivation shows that the permanent axial strain $\mathcal{E}_{l}^{p^{*}}(N)$ can be expressed with the modulus $E_{100}^{r}, E_{l i m}^{r}$ and $E_{100}^{s}$ and the parameter $D$. The modulus

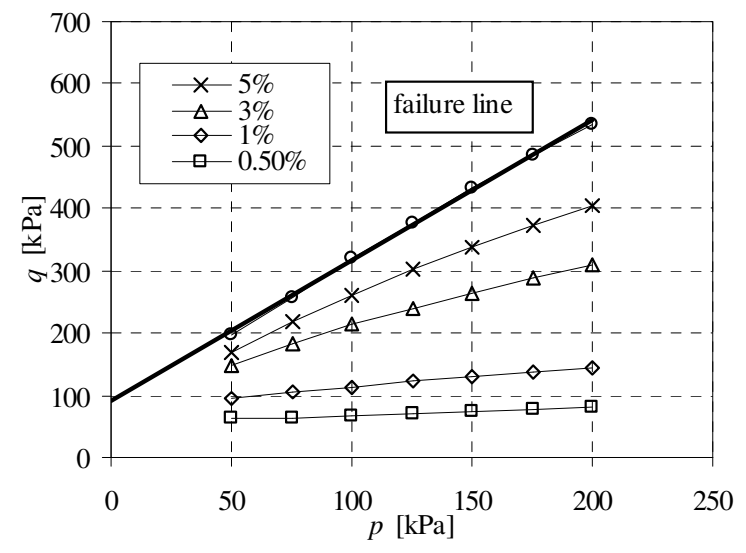

Fig. 5: Failure envelopes and deformation envelopes for different values of the normalized axial permanent strain $\varepsilon_{I}^{p^{*}}$

$E_{100}^{r}, E_{\text {lim }}^{r}$ and $E_{100}^{s}$ are expressed as a function of the spherical stress component $p$ and the distortional stress component $q$. The magnitude of the permanent axial strain $\varepsilon_{I}^{p^{*}}(N)$ depends on the value of $E_{\text {lim }}^{r}$ and ratios between the modules. The parameter $D$ gives the shape of the change of the permanent axial strain $\varepsilon_{l}^{p^{*}}(N)$ with the number of cycles $N$ and is a function of modulus changes with the number of cycles $N$ and ratios between the modules.

The applicability of the presented model is demonstrated on the practical example of repeated load triaxial tests of sub-grade granular material.

\section{REFERENCES}

1. Barksdale RD., 1972. Laboratory evolution of rutting in base cours material, Proc. of 3. Int. Conf. on Structural Design of Asphalt Pavements, London, 161-174

2. Hornych P, Corte JF, Paute JL., 1993. Etude des déformations permanentes sous chargements répétés de trois graves non traitées. Bulletin de liaison des Laboratoires des Ponts et Chaussées, 184, 45-55. 
3. Zlender, B., et.al, 2001. Repeating load tests of pavement granular base material. Research Project - DARS, University of Maribor.

4. Pavsic P., Petkovsek A., 2004. The use of Mura region gravel for pavements, final report. ZAG Ljubljana, University of Ljubljana.

5. Zlender, B., et.al, 2006. Cyclic triaxial tests. Research Project - Prevent, Ministry of higher education, science and technology, University of Maribor.

6. Hicks RG, Monismith CL., 1972. Prediction of the resilient response of pavement containing granular layers using nonlinear elastic theory. International Conference on Asphalt Pavement, 1: 410-429.

7. Boyce H. R., 1980. A non linear model for the elastic behavior of granular materials under repeating loading, International Symposium on Soils under Cyclic and Transient Loading, Swensea, vol. 1, 285-294.
8. Uzan J. et al, 1992. Development and validation of realistic pavement response models, 7.ICAP, Nottingham, p. 334-350.

9. NF P98-235-1 (1995): Essais relatifs aux chaussées - Matériaux non traités - Partie 1: essai triaxial à chargements répétés, $\mathrm{AFNOR}$

10. SIST EN 13286-7, 2004. European Standard: Unbound and hydraulicaly bound mixtures - Part 7. Repeated load triaxial test for unbound mixtures

11. Zlender, B., Macuh, B., 2003. Response of pavement granular base material on repetitional traffic loads. Proceedings of the XIIIth European conference on soil mechanics and geotechnical engineering, Prague, vol. 2, 929-938.

12. Ficko, G., Zlender, B., 2005. The analysis of permanent deformations for cyclic loaded Mura gravels. Acta Geotechnica Slovenica, vol. 2, 2231. 